\title{
ENCAPSULATION OF Lactobacillus reuteri AND USE IT IN THE PRODUCTION OF LACTIC ACID BY WHEY. Ibrahim, S. ${ }^{1}$; M.M.Eid ${ }^{3}$; C. Kim ${ }^{1}$ and A. Shahbazi ${ }^{2}$ \\ 1 Department of Family and Consumer Sciences, 161 Carver Hall \\ 2 Department of Natural Resources and Environmental Design. North Carolina A\&T State University, Greensboro, NC \\ 3 Department of Dairy Science National Research Center, Dokki, Cairo, Egypt.
}

\begin{abstract}
Lactic acid (LA) is the most widely used multifunctional organic acid and approximately $50 \%$ of it is produced by biotechnological process. Immobilizing microbial cells not only improves cell retention but also protects cells from harsh environment conditions during LA production. A great amount of whey is produced as byproduct worldwide in the manufacture of cheese or casein and its disposal has been an issue of environmental pollution. The objectives of this research were therefore to develop a simple method to encapsulate (immobilize) Lactobacillus reuteri for the continuous production of LA and to evaluate LA production in the whey based medium compare with MRS and modified MRS media using free and immobilized $L$. reuteri. Five strains of $L$. reuteri grown in lactobacillus MRS broth at $37^{\circ} \mathrm{C}$ for $24 \mathrm{~h}$ were washed in peptone water and suspended in $2 \%$ sodium alginate solution. Encapsulation of cells was performed by dripping the mixture of sodium alginate and culture into ice-cold $\left(2^{\circ} \mathrm{C}\right) 0.4 \mathrm{M}$ calcium chloride solution using a separator funnel. The beads were then subjected to each of $500 \mathrm{ml}$ MRS, modified MRS and whey-based broth and then incubated at $37^{\circ} \mathrm{C}$ for $12 \mathrm{~h}$. Samples were withdrawn at $2 \mathrm{~h}$ intervals during incubation period and analyzed for LA as represented in $\mathrm{pH}$. Results show that the developed method is a rapid and simple microbial encapsulation procedure for the continuous production of LA. The efficacy of LA production as measured in $\mathrm{pH}$ was not significantly different in all tested media. At the end of fermentation process, $\mathrm{pH}$ of whey medium containing conventional (free) and encapsulated cells reached to 4.20 and 3.85 , respectively. This indicates that higher amount of acid is yielded with encapsulated cells than free cells. In addition, immobilized cell strain MM2-3 produced the highest lactic acid $(\mathrm{pH} 3.5)$ while free cell strain SD2112 produced the lowest lactic acid $(\mathrm{pH}$ 4.05). Hence, results from this study suggest that we were able to develop a simple and rapid method for the encapsulation of $L$. reuteri.
\end{abstract}

Keywords: encapsulation, L.reuteri, whey. 


\section{INTRODUCTION}

LA is widely used in the food, pharmaceutical and chemical industries (Newman and McBurney, 2004). Several species of lactic acid bacteria (LAB) have been commercially used for LA production through the fermentation process of sugars, typically glucose (Wee et. al., 2006). One of the expanding industrial applications of LA is polymerization of LA to polylactic acid (PLA), which is used to manufacture a variety of products, including biodegradable plastics and textile fiber (Wee et. al., 2006). These applications have increased interest in developing more efficient production for LA.

Several technologies have been used for the efficient production of LA. One of those methods is a conventional batch fermentation process, which results in low rates of cell growth and productivity due to its inhibitory acid accumulation. Therefore, immobilization of viable LAB has attracted considerable interest for a decade. Successful microencapslation depends on the right selection of the wall-material and encapsulation technique for a specific core material (Scannell, et. al., 2000). Many properties of the microencapsulated system such as the retention of viable bacteria cells or the protection of core materials are related to the porosity and the integrity of the microcapsules (Scannell, et. al., 2000). Chronopoulous et al. (2002) and Champagne et al. (1987) also observed that cell growth in core coated with gelatine after immobilization yielded high cell concentrations per gram of encapsulated support system and immobilization of LAB by entrapment within a gel bead greatly improved LA production.

Calcium alginate due to its low cost has been commonly used to immobilize LAB for the production of LA (Elezi et. al., 2003; Kyung et. al., 2003). The most common method used to encapsulate LA cells into corecoated capsules is through syringe needle injection using airless spray gun (Kyung et. al., 2003; Scannell et. al., 2000). In this method, bacteria cells are pumped through a needle to generate droplets which are then collected in ice cold calcium chloride solution. However, this method may produce beads that are less uniform in diameter size and shape.

A great amount of whey is produced as a byproduct worldwide in the manufacture of cheese or casein and its disposal has been an issue of environmental pollution. In general, the manufacture of one ton cheese or casein produces 8 or 25 tons of whey, respectively. The biochemical oxygen demand of whey is approximately $35,000-45,000 \mathrm{~g} / \mathrm{L}$ and therefore, $100 \mathrm{~L}$ of whey have a polluting strength equivalent to the sewage produced by 45 people (Swaisgood, 1982). However, whey contains a wide range of biologically active proteins (enzymes, vitamin-binding proteins, metal-binding proteins, immunoglobulin, etc.), lactose, minerals and water-soluble vitamins (IDF, 1991), which may serve as a fermentable medium for the production of LA.

Objective. The objectives of this research were 1) to develop a simple and rapid method to uniformly encapsulate $L$. reuteri cells for the production of $L A, 2)$ compare whey based broth with two different types of MRS broth as 
fermentation medium for the production of LA, and 3) evaluate production of LA using free and immobilized cells.

\section{MATERIALS AND METHODS}

\section{Bacterial strains and their preparation}

Five strains of L. reuteri (CF2F, DSM20016, MM2-3, MM7 and SD2112) obtained from Biogaia Biologics, Inc. (Raleigh, NC) were used in the study. Each strain was cultured individually in $10 \mathrm{ml}$ of whey broth and incubated at $37^{\circ} \mathrm{C}$ for $24 \mathrm{~h}$.

\section{Media}

Whey, MRS and modified MRS (mMRS) broth were used for this study. Whey broth was consisted of $34 \%$ premium deproteinized whey (60 $\mathrm{g} / \mathrm{L}$, Davisco, Foods International Inc., Le Sueur, MN), yeast extract (2.5 g/L, Sigma-Aldrich Co., St. Louis, MO), L-cysteine hydrochloride anhydrous (0.5 $\mathrm{g} / \mathrm{L}$, Sigma-Aldrich), manganese sulphate $(0.03 \mathrm{~g} / \mathrm{L}$, Thermo Fisher Scientific, Fair Lawn, NJ), and tween 20 (1 ml/L, Thermo Fisher Scientific). Modified MRS (mMRS) was prepared with MRS broth $(55 \mathrm{~g} / \mathrm{L}$, DifcoTM Lactobacilli MRS broth, Becton Dickson and Co., Sparks, MD), manganese sulphate $(0.05 \mathrm{~g} / \mathrm{L})$, tween $20(5 \mathrm{ml} / \mathrm{L})$, and L-cysteine chloride hydrochloride anhydrous $(0.5 \mathrm{~g} / \mathrm{L})$. MRS broth was prepared with MRS broth $(55 \mathrm{~g} / \mathrm{L})$ and $\mathrm{L}$-cysteine chloride hydrochloride anhydrous $(0.5 \mathrm{~g} / \mathrm{L})$. The broth was then autoclaved at $121^{\circ} \mathrm{C}$ for $15 \mathrm{~min}$.

\section{Immobilization procedure}

Overall procedure of cell immobilization was shown in Fig. 1. A 72-h culture of each strain with cell density $\left(A_{610}\right)$ of 1.2 containing $1.2 \times 10^{6} \mathrm{CFU} / \mathrm{ml}$ was centrifuged (Sorvall RC5B plus, Thermo Scientific, Asheville, NC) for 10 $\min$ at $4^{\circ} \mathrm{C}(5,000 \times \mathrm{g})$. The pellets were washed with sterile $1 \%$ peptone water and mixed with $2 \%(\mathrm{w} / \mathrm{v})$ sodium alginate (Sigma-Aldrich Co.). The homogenous mixture of the bacterial cell suspended in alginate solution was then extruded drop by drop into $0.4 \mathrm{M}$ calcium chloride solution (Thermo Fisher Scientific) at pH 7.1 using a $500 \mathrm{ml}$ separatory funnel (ID: $1 \mathrm{~cm}$, Kimax, Kansas City, MO). Beads were slowly stirred on a magnetic stirrer (Thermo Fisher Scientific) at a speed setting of $<3 \mathrm{rpm}$. After completion, the beads were rinsed with sterile $1 \%$ peptone water and were allowed to be further hardened for $30 \mathrm{~min}$ at $4^{\circ} \mathrm{C}$. 
Ibrahim, S. et al.
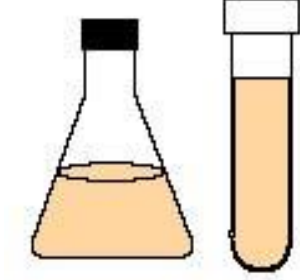

1. The inoculted medis is centr ifuged at $5 K \mathrm{rmp}$ at $4{ }^{\circ} \mathrm{C}$

2. The Supernant is decanted and resuspended with $10 \mathrm{~m}$ of $1 \%$ peptonewater and oentrifuged.

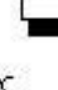

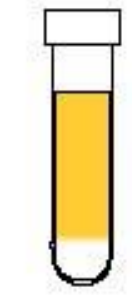

A berategel

inoculated with bacteria

inoculated with bacteria
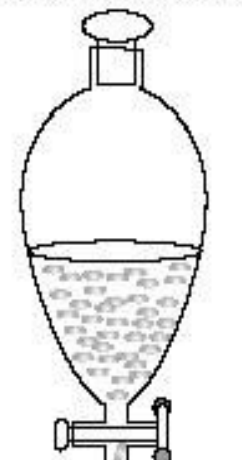

पदी

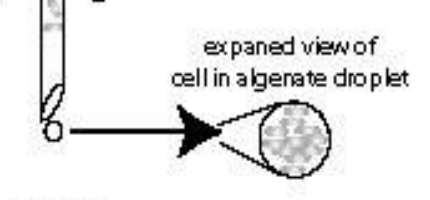

3. The pep to ne water wash is descanded and resuspend. ed with $1 \%$ peptonewater and added to a lgenate gel
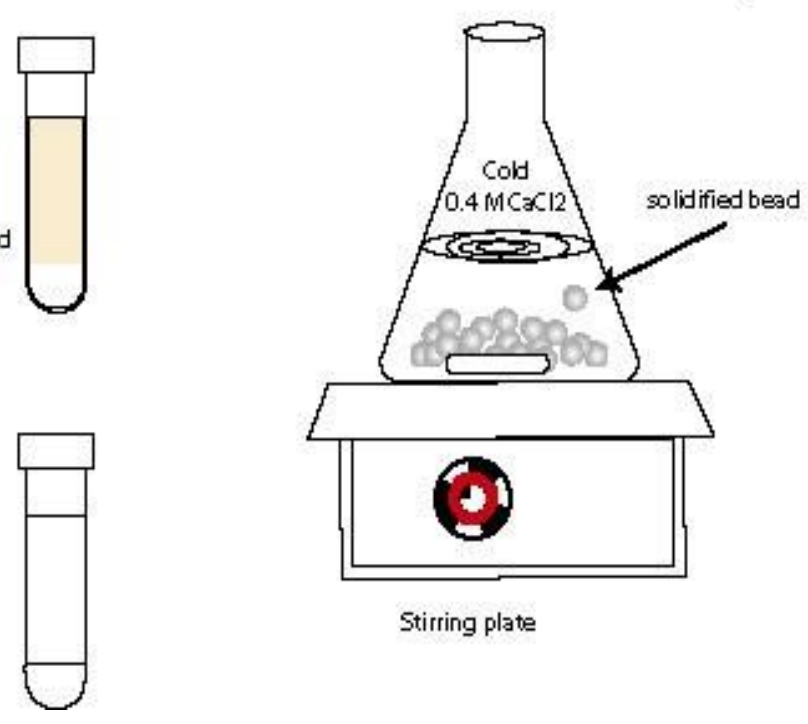

B

Figure 1. Cell immobilization procedure.

\section{Bead uniformity}

Surface area and volume measurements of individual beads were based on water displacement method in which 17 beads were dropped into 3 $\mathrm{ml}$ water in a graduated cylinder, in which water rise was observed and recorded for calculation. Bead integrity was determined based on maximum force $(\mathrm{N})$ needed to rupture the outer surface of individual bead using a Texture Analyzer (TA-XT2, Texture Technologies Co., Scarsdale, NY). The study was carried out at room temperature $\left(24 \pm 2^{\circ} \mathrm{C}\right)$. 


\section{Comparison of batch free and immobilized cell fermentation systems}

A $2.5 \mathrm{ml}$ either immobilized beads or free cells of the five individual strains of $L$. reuteri was inoculated into $500 \mathrm{ml}$ of whey, MRS and mMRS broth, respectively, and incubated $12 \mathrm{~h}$ at $37^{\circ} \mathrm{C}$ for fermentation. The production of LA was then determined as monitored by changes in $\mathrm{pH}$ of both fermentation systems. The $\mathrm{pH}$ of samples were analyzed every $2 \mathrm{~h}$ during 12 $\mathrm{h}$ fermentation process using a $\mathrm{pH}$ meter (Accumet AR 60, Thermo Fisher Scientific).

\section{Statistical analysis}

All experiments were replicated three times. Data were analyzed by the general linear model procedure of the Statistical Analysis System procedures. Comparisons of means were performed using Duncan's multiple range test.

\section{RESULTS AND DISCUSSION}

Bead uniformity study indicated that beads manufactured by the developed simple and rapid method were uniform in size and shape with average diameter of $3.53 \pm 0.10 \mathrm{~mm}$, surface area of $39.13 \pm 0.10 \mathrm{~mm}^{2}$ and volume of $1012.57 \pm 0.10 \mathrm{~mm}^{3}$ (Table1). The results also illustrated that the maximum force of $30.10 \mathrm{~N}$ and time of $3.53 \mathrm{~s}$ were required to rupture the outer surface of gel coating of beads. However, the other work has shown that larger microcapsules are better able to protect bacteria inside, Lee and Heo 2000 reported that large alginate capsules $(2.63 \mathrm{~mm})$ offered more protection to Bifidobacterium longum cells against acid challenge than smaller capsules $(1.03 \mathrm{~mm})$. On the other hand the larger size of capsules may have afforded additional physical protection simply by increasing the distance between encapsulated and the acid, while the increased resistance of organisms in alginate microcapsules to acid challenge may have been in part due to the protective nature of the polymer networks generated during capsule formation (Muthukumarasamy et al..,2006)

Changes in the $\mathrm{pH}$ of whey, MRS, and mMRS broth used for the growth of immobilized $L$. reuteri strains during $12 \mathrm{~h}$ fermentation were shown in Figure 2. Batch immobilized cell (bead) study on the production of LA as represented in $\mathrm{pH}$ changes revealed that there was no significant difference of LA production among whey, MRS and mMRS medium during $12 \mathrm{~h}$ fermentation process (Fig 2). In other words, whey may be utilized as a cheaper alternative for LA production to commercial MRS and mMRS. Several scientists (Lui et al., 2005 and IDF, 1991) indicate that whey contains a wide range of enzymes, proteins, and lactose and therefore may be a suitable nitrogen and carbon source for the growth of $L A B$ while the addition of yeast extract and manganese $\left(\mathrm{Mn}^{2+}\right)$ improves the production of lactic acid. Chronopouls et al.,2002 reported that the lactic acid bacteria have been require the presence of proteinic digeses like yeast extract for production lactic acid, while Zhang and Kelly 2007 they found that the organic nitrogen sources were relatively less favourable for lactic acid production when they used Rhizopus arrhizus for production. 
Ibrahim, S. et al.

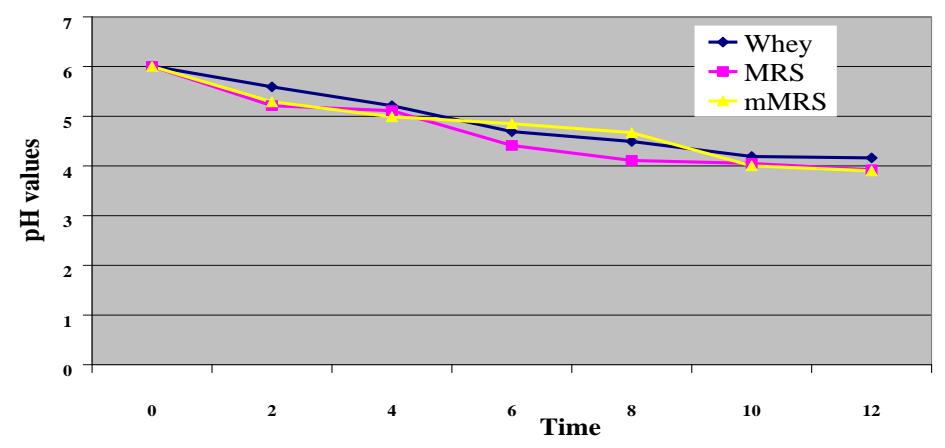

Figure. 2: Changes in $\mathrm{pH}$ during $12 \mathrm{~h}$ fermentation of immobilized $L$. reuteri (DSM20016) using three different medium (whey, MRS and mMRS broth) at $37^{\circ} \mathrm{C}$.

Effect of cell immobilization by five strains of $L$. reuteri on the $\mathrm{pH}$ of whey broth during $12 \mathrm{~h}$ fermentation at $37^{\circ} \mathrm{C}$ was shown in Table 1 . When whey broth was inoculated with each of five strains of $L$ reuteri and subjected to $12 \mathrm{~h}$ fermentation process, on average, lower $\mathrm{pH}(\sim 3.85)$ values were obtained from the media inoculated with immobilized cells than those $(\sim 4.20)$ of free cells. These results are in accordance with the findings of Elezi et al. (2003) that LA production using immobilized cell system, particularly calcium alginates, improved yields in comparison to free cell systems. Moreover, Table 1 indicated that $\mathrm{pH}$ reading obtained by fermentation of both free and immobilized MM2-3 was the lowest and therefore the strain might be more acid-tolerant and could be used more effectively for the production of LA than other strains used in this study.

Table 1. Bead stability data

\begin{tabular}{|l|c|c|c|}
\hline Group & Max Force(g) & Time(sec.) & Diameter(mm) \\
\hline 1 & 2795.0 & 2.940 & 2.940 \\
\hline 2 & 3296.1 & 4.025 & 3.995 \\
\hline 3 & 3116.0 & 3.635 & 3.654 \\
\hline
\end{tabular}

Table 2. Effect of cell immobilization by $L$. reuteri strains on the $\mathrm{pH}$ of whey broth during $8 \mathrm{~h}$ fermentation at $37^{\circ} \mathrm{C}$.

\begin{tabular}{|c|c|c|c|c|c|}
\hline \multirow{2}{*}{} & Cell type & \multicolumn{4}{|c|}{ pH due to fermentation time (h) } \\
\cline { 3 - 5 } & & 2 & 4 & 8 & 12 \\
\hline \multirow{2}{*}{ CF2F } & Free & 5.20 & 4.40 & 4.40 & 4.40 \\
\cline { 2 - 5 } & Immobilized & 4.00 & 4.00 & 4.00 & 3.98 \\
\hline \multirow{2}{*}{ DSM20016 } & Free & 4.95 & 4.30 & 4.30 & 4.30 \\
\cline { 2 - 5 } & Immobilized & 4.20 & 4.10 & 4.00 & 3.98 \\
\hline \multirow{2}{*}{ MM2-3 } & Free & 4.78 & 4.18 & 4.10 & 4.00 \\
\cline { 2 - 5 } & Immobilized & 3.82 & 3.50 & 3.50 & 3.50 \\
\hline \multirow{2}{*}{ MM7 } & Free & 5.10 & 4.30 & 4.20 & 4.20 \\
\cline { 2 - 5 } & Immobilized & 3.70 & 3.70 & 3.70 & 3.70 \\
\hline \multirow{2}{*}{ SD2112 } & Free & 5.20 & 4.30 & 4.20 & 4.10 \\
\cline { 2 - 5 } & Immobilized & 4.20 & 4.10 & 4.10 & 4.10 \\
\hline
\end{tabular}

"Initial pH of whey broth was 7.00. 


\section{Conclusion}

The combination of $L$. reuteri (strain MM2-3) and whey based medium makes batch bead fermentation a promising and economical approach for high production of LA. Our results show that we were able to develop a simple and rapid method for the encapsulation of $L$. reuteri. The addition of tween 20 to whey medium helped substrate diffusions and therefore increased LA productivity. Overall, based on the promising results found from this study on the application of cell immobilization and whey utilization to the production of LA, further research on alternative supplements promoting the growth of $L A B$ is suggested.

\section{REFERENCES}

Champagne, P. C., and B. C. Cote. 1987. Cream fermentation by immobilized lactic bacteria. Biotechnol. Lett. 9, 329-332.

Chronopoulous, G., A. Bekatorou, E. Bezirtzoglou, A. Kaliafas, A. A. Koutinas, R. Marchant and I. M. Banat. 2002. Lactic acid fermentation by Lactobacillus casei in free cell form and immobilized on gluten pellets. Biotechnol. Lett. 24, 1235-1236.

Elezi O., Y. Kourkoutas, A. A. Koutinas, M. Kanellaki, E. Bezirtzoglous, Y. A. Barnett, and P. Nigam P. 2003. Food additive lactic acid production by immobilized cells of Lactobacillus brevis on delignified cellulosic material. J. Agric. Food Chem. 51, 5285-5289.

International Dairy Federation(IDF) 1991. Significance of the indigenous antimicrobial agents of milk to the dairy industry. Int. Dairy Fed.Bull.No. 264, 2-19.

Kyung, W. L., C. B. Seung, H. C. Woon, and W. K. Hyun. 2003. Structural observation of microencapsulated Lactobacillus acidophilus by optical and scanning electron microscopy. Food Sci. Biotechnol. 12, 14

Lee,K.Y. and T.R. Heo 2000.Survival of Bifidibacterium longum immobilized in calcium alginate beads in simulated gastric juices and bile salt soulation. Appl. Environ. Microbiol. 66: 869-873.

Lui, X., Y. K. Chung, S. T. Yang, and A. E. Yousef. 2005. Continuous nisin production in laboratoery media and whey permeate by immobilized Lactococcus lactis. Process Biochem. 13-24.

Muthukumarasamy, P.; Wojtas, P.A. and R.A. Holley 2006. Stability of lactobacillus reuteri in different types of microcapsules. J. Food. Sci. 71:20-24

Newman, K. D. and M. W. McBurney. 2004. Poly (D, L lactic-co-glycolic acid) microspheres as biodegradable microcarriers for pluripotent stem cells. Biomaterials. 25, 5763-5771.

Scannell, A. G. M., C. Hill, R. P. Ross, S. Marx, W. Hartmeier, and E. K. Arendt. 2000. Continuous production of lacticin 3147 and nisin using cells immobilized in calcium alginate. J. of Appl. Microbiol. 89, 574576. 


\section{Ibrahim, S. et al.}

Swaisgood, H. E. 1982. Chemistry of milk proteins. In: P. F. Fox (Eds.). Developments in dairy chemistry. 1, 1-60. Applied Science Publishers, New York. 1-60.

Wee, Y. J., J. N. Kim, J. S. Yun, D. H. Park, and H. W. Ryu. 2006. Pilot-scale lactic acid production via batch culturing of Lactobacillus sp. RKY2 using corn steep liquor as a nitrogen source. Food Technol. Biotechnol. 44, 293-298.

Zh ang Z.Y. ; Jin B. and Kelly J.M. (2007) Production of lactic acid and byproducts from waste potato starch by Rhizopus arrhizus :role of nitrogen sources. World J. Microbiol Biotechnol 23:229-236.

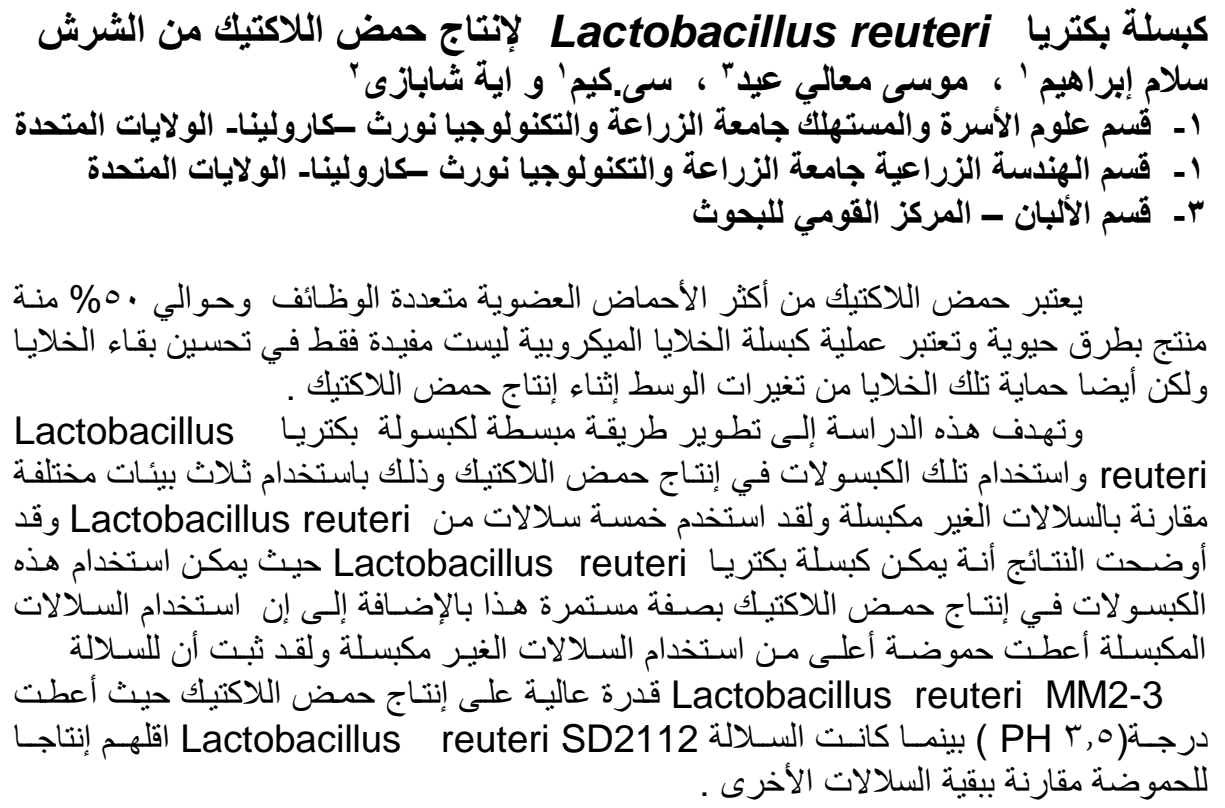

